\section{The Lords fall down}

SIR - I fear that the recently published report (see Nature 361, 481; 1993) on the Faraday programme falls short of the high quality we have come to expect from the House of Lords Select Committee on Science and Technology, which has missed a significant opportunity to influence national thinking on innovation. I could more readily accept the committee's rejection of the proposals of this centre's working group if the committee had offered some new ideas to improve the innovative capacity of small and medium sized companies rather than attempting to maintain the status quo.

Any survey of this type depends, of course, on the sample and the universe from which it is drawn. Industry represented just 15 per cent of the sample and half of these companies were from the chemical and pharmaceutical industries, sectors which we clearly stated in our reports and our evidence were unlikely to find merit in the proposals. In none of the working group's reports are new buildings proposed and we made it abundantly clear that any organization could be considered, including higher education institutes and industry laboratories, provided they satisfied the criteria, which are extensive interaction with industry, an established industrial customer base and an international reputation, and a track record in technology development and transfer.

The Faraday programme is primarily intended to improve the performance of medium-sized companies employing fewer than 500 people. I do not doubt that larger enterprises would benefit, but for the committee to interview only multinationals was a mistake. The Department of Trade and Industry (DTI) has conducted a similar review of attitudes amongst industrialists, including SMEs (small and medium-sized establishments), and I have a great deal more confidence in their validity.

The main categories from which the sample is drawn were government and institutes of higher education, although I note that the committee failed to interview any of the former polytechnics. Given that there was little prospect of new money, I am not surprised that government officials were noncommittal and the academics afraid of seeing their funding reduced still further.

Throughout the report there is little mention of technology development, the very essence of the Faraday concept. There appears to be no appreciation that technology is not the same as science and that development is substantially different from research. The development of generic or enabling technologies for industry is not the prime objective of universities nor of any of the schemes mentioned in the report. LINK comes closest but I still believe that, for many medium companies, the prospect of dealing with a university is too daunting.

The report refers to a culture change within universities. I accept that they are beginning to appreciate their role in improving the competitiveness of industry, but many academics rightly perceive a conflict between maintaining a high research profile and extensive interaction with industry. The report suggests the large number of university-based collaborations bears testimony to this culture change. Relative to the scale of the challenge, I do not believe numbers are large and research clubs and parttime $\mathrm{PhDs}$ are of little consequence.

The select committee's report was published at a critical time, with the Office of Science and Technology and the DTI undertaking fundamental reviews and industry under pressure to create wealth and rescue the economy. The old ways have failed. My group identified a way out of the impasse and the debate has moved on. The Faraday principles have been widely endorsed, not least by the Secretary of State for Trade and Industry in his evidence to the committee. The DTI is looking to remove barriers to the participation of institutions intermediate between industry and the science base in various schemes.

Meanwhile, universities and technology development organizations throughout Britain are developing new relationships, incorporating the principles into new partnerships and seizing the opportunity to serve industry in imaginative and effective ways. The select committee has missed the opportunity to assist this process. As the provost of University College London said in evidence, "part of the British disease is to do nothing whilst considering the options".

\section{John Fairclough}

(Chairman, Working Group on Innovation) Centre for Exploitation

of Science and Technology,

5 Berners Road, London N1 OPW, UK

\section{Working for a test-ban treaty}

SIR - Lord Zuckerman's article (Nature 361, 392-396; 1993) is a timely reminder that Britain should again be working for an early Comprehensive Test Ban (CTB) Treaty. It may be helpful if I clarify one point in the leading article in the same issue (page 381).

Referring to the CTB negotiations of
1977-80, which incidentally covered all but the first six months of President Carter's term, you say "But that treaty, which would have been signed by Britain, the Soviet Union and the United States, would not have met the present need". My own belief (as deputy leader and then leader of the UK delegation to the CTB negotiations in Geneva from 1977 to 1980), and that of former US negotiators I have spoken to this year, is that the main features of the treaty we were negotiating and drafting would meet the present need very well. We always made it clear that, once the three negotiating powers had agreed on a draft, it would go to the Conference on Disarmament and thence to the UN General Assembly for approval. It would then be open for signature by all states.

The main difference now is that the other two declared nuclear powers acceded to the Non-Proliferation Treaty in 1992 and could therefore logically join the original three in negotiating a CTB. There seems every prospect that France will wish to do so, and no doubt China would be welcome to join at any stage.

The important thing is to avoid providing excuses for still further delay in achieving a treaty to which Britain has been committed for some 30 years. The latest excuses tend to emphasize "safety", about which Zuckerman makes some telling comments. His doubts are reinforced by a recent statement by a number of eminent US nuclear scientists that "the advantages of an immediate mutual moratorium and of a CTB outweigh, in our judgement, any perceived benefits of further tests for any reason" (my emphasis).

In my judgement, it need not take many months to complete a treaty that would, in your words, be "genuinely comprehensive". This would demonstrate at last that the nuclear powers are prepared to accept restraints on their own nuclear weapon programmes and so greatly improve the case for preventing the further spread of such weapons. The main requirement now is not a technical one - it is the political will of the countries most concerned, and that includes Britain.

J. C. Edmonds

North Lodge,

Sonning, Berkshire RG4 OST, UK

SIR - In the picture on page 395 of Yeltsin and Bush signing START 2 in Moscow, Yeltsin holds the pen in his left hand; Bush holds the pen in his right with the typical left-hander's arm curl. No wonder it looks odd: the picture is reversed.

David L. Wagger

1021 Arlington Blvd, Apt 641,

Arlington, Virginia 22209-2228, USA 